\title{
STUDY OF CRACKS FORMATION IN HIGHLY - LOW BORON-DOPED EPITAXIAL (113) DIAMOND BILAYERS
}

\author{
1,2Vincent MORTET, 'Ladislav KLIMSA, ${ }^{1,3}$ Nicolas LAMBERT, ' Marina DAVYDOVA, \\ 1'Jaromir KOPECEK, ${ }^{1}$ Silvia IGNACOVA SEDLAKOVA \\ ${ }^{1} \mathrm{FZU}$ - Institute of Physics of the Czech Academy of Sciences, Prague, Czech Republic, EU, mortetv@fzu.cz \\ ${ }^{2}$ Faculty of Biomedical Engineering, Czech Technical University in Prague, Kladno, Czech Republic, EU \\ ${ }^{3}$ Faculty of Electrical Engineering, Czech Technical University in Prague, Prague, Czech Republic, EU \\ lambenic@fel.cvut.cz
}

https://doi.org/10.37904/nanocon.2021.4326

\begin{abstract}
In this work, we present the study of the formation of cracks in high and low boron-doped diamond epitaxial bilayers necessary in the fabrication process of Schottky diodes. Epitaxial diamond layers were grown on (113) oriented diamond substrates by Microwave Plasma Enhanced Chemical Vapor Deposition. The effect of the thickness and the methane concentration during the growth of the undoped diamond layer on the crack formation have been studied using optical and scanning electron microscopy (SEM). We experimentally observed a critical thickness of ca. $3.5 \mu \mathrm{m}$ above which all undoped layers are cracked. The formation of these cracks is attributed to the relaxation of the elastic energy stored in the epitaxial undoped layer due to the significant lattice mismatch (ca. $0.8 \%$ ) between the undoped and highly boron-doped diamond layers with a boron concentration of $10^{21} \mathrm{~cm}^{-3}$ as determined by Raman spectroscopy analysis.
\end{abstract}

Keywords: Diamond, boron-doping, epitaxy, cracks

\section{INTRODUCTION}

Many acknowledge diamond as the best wide-bandgap semiconductor for fabricating high-performance, high power, and high-frequency electronic devices due to its outstanding properties. Yet many scientific and technical issues must be resolved before the realization of reliable diamond electronic devices. Recent studies have demonstrated the interest in (113) epitaxial diamond layers in the fabrication of diamond electronic devices as this crystalline orientation offers better surface morphology, higher growth rate, high boron incorporation efficiency, lower surface roughness and defect-free surface in comparison with (100) and (111) orientations [1-3]. The fabrication process of semi-vertical diamond Schottky diodes requires the growth of epitaxial doped diamond bilayer with low and high dopant concentrations, which is the second necessary step in fabricating diamond electronic devices like Schottky diodes. However, the fabrication of boron-doped diamond bilayer structure is not straightforward due to cracks in the diamond epitaxial layer preventing the final realization of Schottky diodes. This work studies the formation of cracks in non-intentionally doped diamond epitaxial bilayers deposited on a heavily boron-doped (113) oriented diamond layer.

\section{EXPERIMENTAL}

Epitaxial boron-doped diamond bilayers were grown on (113) oriented high-pressure high-temperature substrates in a commercial AX5010 microwave plasma-enhanced chemical vapor deposition (MWPECVD) reactor from Seki Diamond Systems using the deposition conditions reported in Table 1. A ca. $5 \mu \mathrm{m}$ thick highly boron-doped epitaxial diamond layer is first deposited on the (113) oriented diamond substrate with a boron to carbon ratio $(\mathrm{B} / \mathrm{C})$ in the gas phase of $2000 \mathrm{ppm}$ for a deposition time of 2 hours. Immediately after 
the flow of the boron precursor (trimethylborane) is stopped, the methane concentration is adjusted to the desired concentration. The methane concentration during this second step has been varied from $0.3 \%$ to $1 \%$. The deposition time of this second layer is variable. The boron concentration of the highly boron-doped diamond layer has been evaluated from the analysis of its Raman spectrum between 1000 and $1500 \mathrm{~cm}^{-1}$ measured at room temperature using a Renishaw InVia Raman Microscope with a $488 \mathrm{~nm}$ excitation laser. The diamond layer thickness is estimated using known deposition rates. The deposition rates were determined from a multilayer boron-doped epitaxial diamond sample characterized by secondary ion mass spectroscopy (SIMS). The formation of cracks on fabricated samples was determined by optical and scanning electron microscope (SEM) using a Zeiss Imager Z1m light optical microscope and a TESCAN FERA3 GM SEM.

Table 1 Deposition conditions of epitaxial boron-doped diamond layers

\begin{tabular}{|c|c|c|c|c|c|c|}
\hline & $\begin{array}{c}\text { Pressure } \\
\text { (mbar) }\end{array}$ & $\begin{array}{c}\text { Microwave } \\
\text { power (W) }\end{array}$ & $\begin{array}{c}\text { Total gas flow } \\
\text { (sccm) }\end{array}$ & {$[$ CH4] (\%) } & B/C (ppm) & $\begin{array}{c}\text { Deposition } \\
\text { time (h) }\end{array}$ \\
\hline \hline $\mathbf{1}^{\text {st }}$ step & 100 & 700 & 700 & 1 & 2000 & 2 \\
\hline $2^{\text {nd }}$ step & 100 & 700 & 700 & variable & 0 & variable \\
\hline
\end{tabular}

\section{RESULTS AND DISCUSSION}
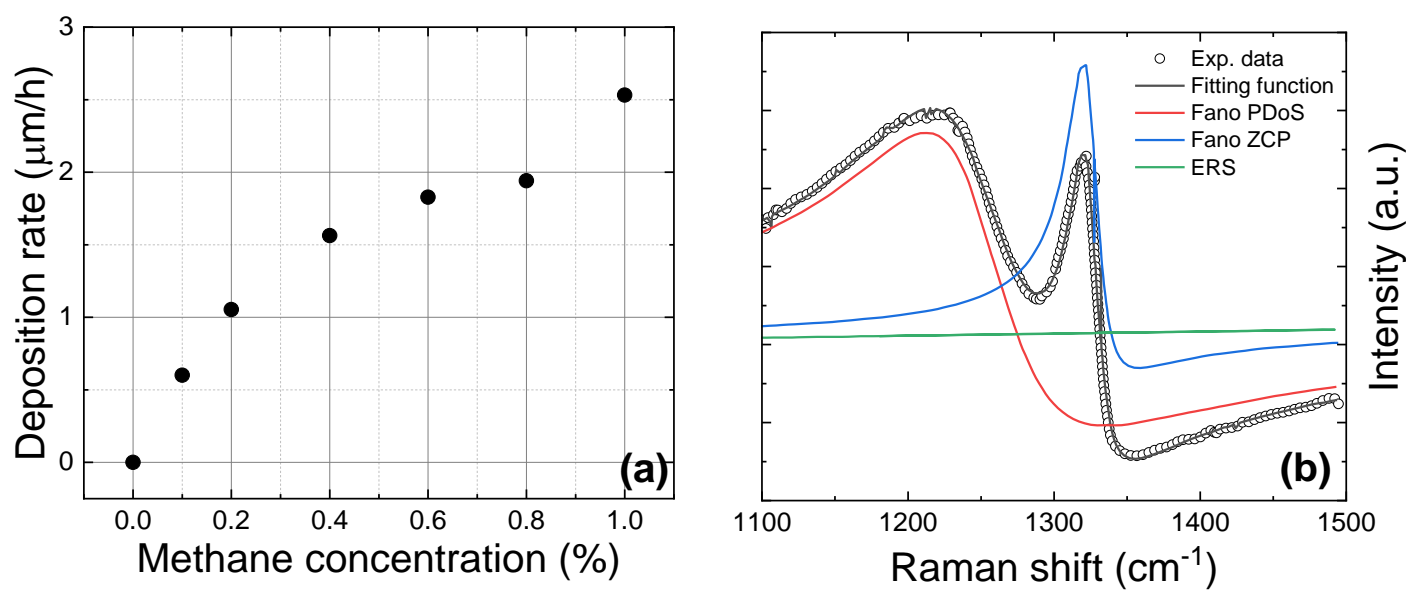

Figure 1 (a) Deposition rate of epitaxial boron-doped diamond as a function of the methane concentration and a boron to carbon ratio of $100 \mathrm{ppm}$ in the gas phase in an AX5010 MWPECVD reactor operating at 100 mbar and 700 Watts (b) Experimental Raman spectrum (Exp. Data) of the epitaxial boron-doped diamond layer grown at a boron to carbon ratio of 2000 ppm and its decoupled double Fano-function fit (fitting function) including electronic Raman scattering (ERS), the Fano shaped zone center phonon diamond line (Fano ZCP) and the Fano shaped maximum of the phonon density of states peak (Fano PDoS).

Figure 1a shows the deposition rate of epitaxial diamond grown on (113) oriented substrates as a function of the methane concentration between 0 and $1 \%$ for a boron to carbon ratio in the gas phase of $100 \mathrm{ppm}$. The growth rate grows sub-linearly with a value of ca. $2.5 \mu \mathrm{m}$ at a methane concentration of $1 \%$. The deposition rate is independent of the boron to carbon ratio up to $2000 \mathrm{ppm}$, as demonstrated by SIMS analysis of epitaxial boron-doped diamond layer prepared with different boron to carbon ratios for the two methane concentrations 0.1 and $1 \%$. Therefore, the thickness of the different diamond layers prepared in this work has been estimated from the growth rate reported in Figure 1a. Figure 1b shows the Raman spectrum of the heavily boron-doped diamond underlayer grown at $\mathrm{B} / \mathrm{C}=2000 \mathrm{ppm}$ between 1100 and $1500 \mathrm{~cm}^{-1}$ with a laser excitation wavelength of $488 \mathrm{~nm}$ and its decoupled double Fano-function fit using the online fitting tool at https://ofm.fzu.cz/cs/raman- 
tool to determine the boron concentration of ca. $10^{21} \mathrm{~cm}^{-3}$ from the width $\left(12.32 \mathrm{~cm}^{-1}\right)$ of the undisturbed zone center phonon line of diamond [4]. This highly boron-doped diamond layer has a low resistivity of $2 \mathrm{~m} \Omega . \mathrm{cm}$, allowing the formation of ohmic contact with a specific contact resistance below $10^{-6} \Omega . \mathrm{cm}^{-2}$ suitable for the fabrication of low ON resistance Schottky diodes [1].
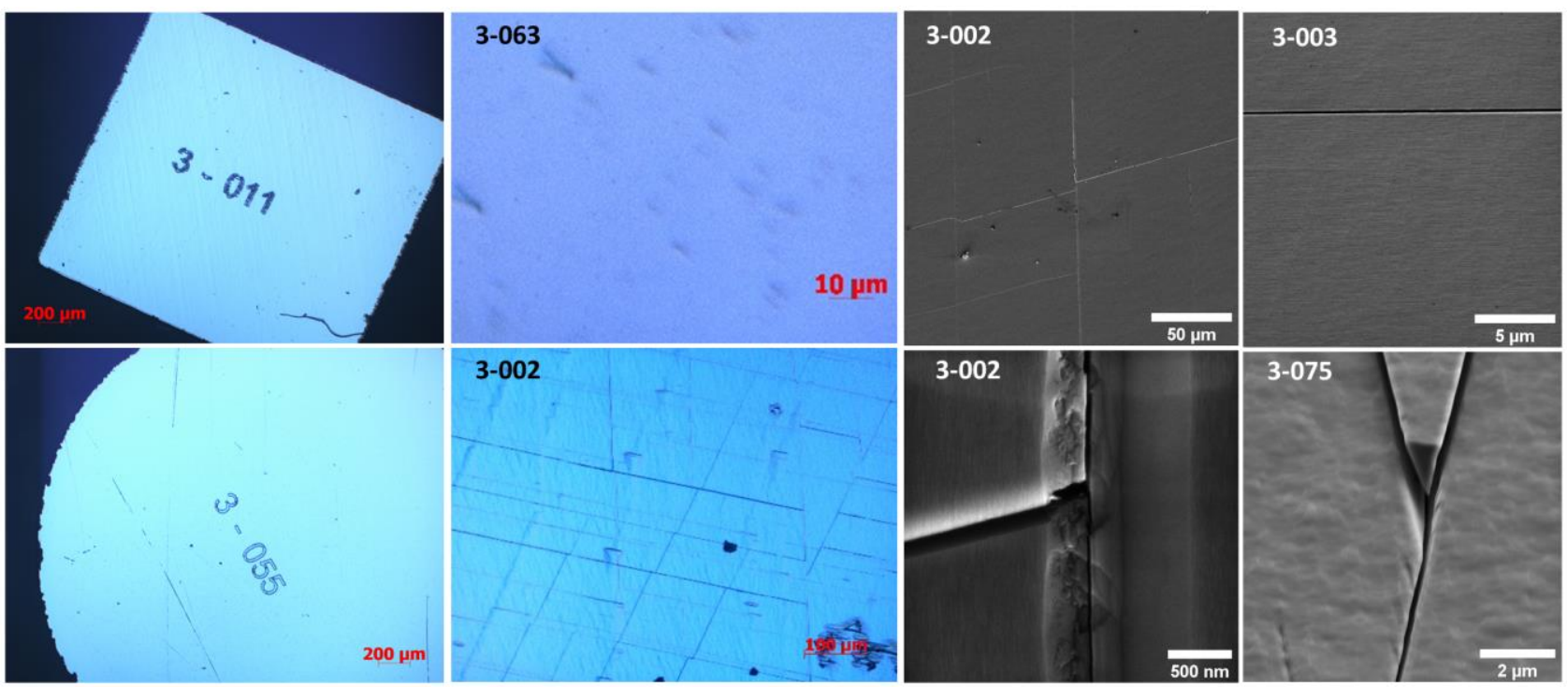

Figure 2 Optical (left) and scanning electron microscopy images (right) of the highly boron-doped/undoped epitaxial diamond bilayers of samples with different thicknesses $(\mathrm{t})$ of the undoped layer $\left(\mathrm{t}_{3-011}<3 \mu \mathrm{m}, \mathrm{t}_{3-055}=\right.$ $\left.1.4 \mu \mathrm{m}, \mathrm{t}_{3-002}=10.1 \mu \mathrm{m} ; \mathrm{t}_{3-063}=5.1 \mu \mathrm{m}, \mathrm{t}_{3-003}=7 \mu \mathrm{m}, \mathrm{t}_{3-075}=7 \mu \mathrm{m}\right)$. Examples of characteristic cracks in higher magnification are shown on samples 3-002 and 3-075 (bottom-right images).
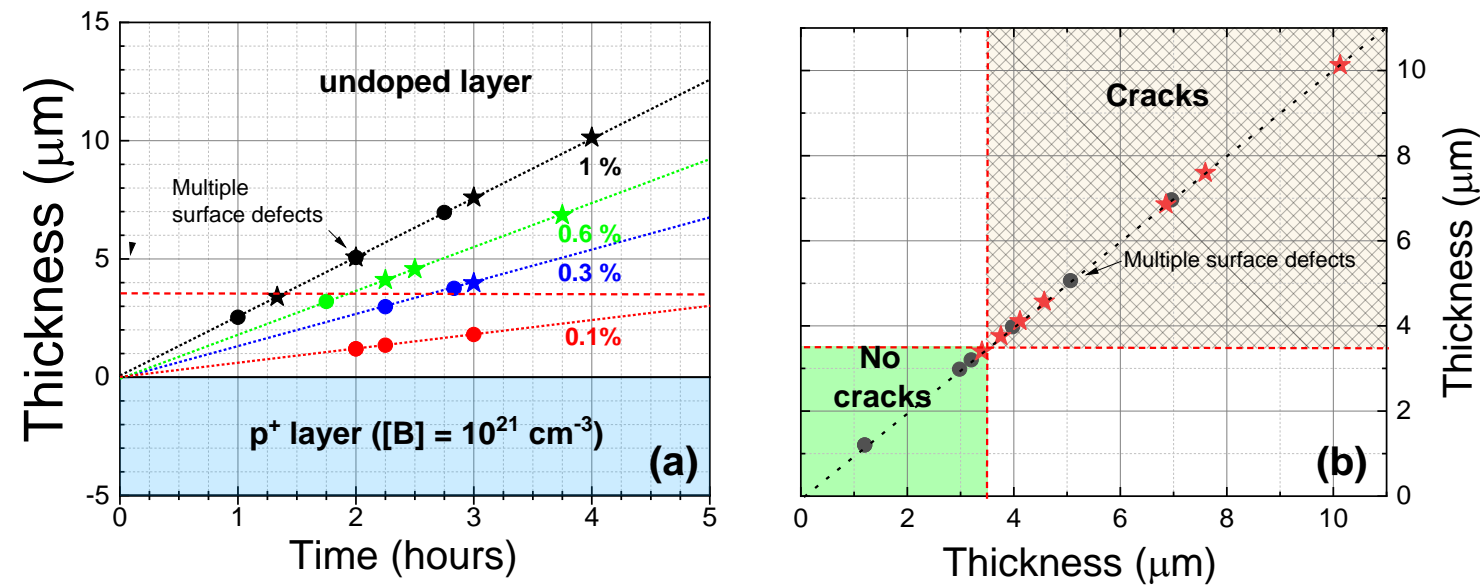

Figure 3 (a) Thickness of undoped diamond layer and observation of cracks (star symbols) or not (dotted symbols) on the sample surface as a function of the deposition time for undoped diamond layers grown with different methane concentrations (b) Graphical representation of the formation of cracks (star symbols) or not (dot symbols) on the surface of the sample as a function of the thickness of the undoped diamond layer independently of the methane concentration during the layer deposition.

Figure 2 (left) shows optical microscopy images of epitaxial diamond bilayers with different undoped diamond layer thicknesses and methane concentrations. Samples with a thin undoped diamond layer (e.g. sample 3-011 and 3-055) are smooth and without the defects observed on conventional (100) or (111) epitaxial layers [5]. They also do not exhibit visible cracks. On the contrary, most thick samples exhibit cracks (sample 3-002) 
or a high density of surface defects (sample 3-063). Figure 2 (right) shows SEM images with detailed morphology of cracks filled by polycrystalline-like diamonds immediately after their formation during the deposition process. Figure $\mathbf{3} \mathbf{a}$ shows the estimated thickness from the deposition time of undoped layer deposited at different methane concentrations on the $5 \mu \mathrm{m}$ thick heavily boron-doped epitaxial layer and if the sample is cracked (star symbol) or not (dot symbol). Apart from the sample with a $7 \mu \mathrm{m}$ thick undoped layer and the 5.1 $\mu \mathrm{m}$ thick 3-063 sample, all samples with a thick undoped layer exhibit cracks on their surface. These results are well illustrated in Figure $\mathbf{3 b}$, which indicates the existence of a critical thickness between 3.5 and $4 \mu \mathrm{m}$ above which the samples are cracked independently on the growth conditions. The formation of these cracks is attributed to the relaxation of the mechanical energy in the undoped diamond layer due to a significant lattice mismatch between the two doped diamond layers.

\section{CONCLUSION}

In this work, highly boron-doped / undoped epitaxial diamond bilayers have been grown by microwave plasmaenhanced chemical vapor deposition technique on (113) oriented single crystal diamond substrates with different thicknesses of the undoped diamond layer and different methane concentrations in the gas phase. The boron concentration is ca. $1021 \mathrm{~cm}^{-3}$ in the $5 \mu \mathrm{m}$ thick highly doped diamond layer as determined from Raman analysis. Optical and scanning electron microscopy investigation shows the formation of cracks unwanted for the fabrication process of Schottky diodes on fabricated bilayers for samples with an undoped diamond layer thickness larger than ca. $3.5 \mu \mathrm{m}$ independently on the methane concentration in the gas phase during the plasma-enhanced chemical vapor deposition. The formation of cracks is attributed to the relaxation of the mechanical energy in the undoped diamond layer due to a significant lattice mismatch between the two doped diamond layers.

\section{ACKNOWLEDGEMENTS}

The Czech Science Foundation primarily supported this work grant No. 20-11140S, the Czech Technical University Student Grant No. SGS20/176/OHK3/3T/13 and Education financed by European Structural and Investment Funds and the Czech Ministry of Education, Youth and Sports (Project No. SOLID21 - CZ.02.1.01/0.0/0.0/16_019/0000760). CzechNanoLab project LM2018110 funded by MEYS $C R$ is also gratefully acknowledged for the financial support of the measurements at LNSM Research Infrastructure.

\section{REFERENCES}

[1] MORTET, V., TAYLOR, A., LAMBERT, N., GEDEONOVÁ, Z., FEKETE, L., LORINČIK, J., KLIMŠA, L., KOPEČEK, J., HUBÍK, P., ŠOBÁŇ, Z., LAPOSA, A., DAVYDOVA, M., VOVES, J., POŠTA, A., POVOLNÝ, V., HAZDRA, P. Properties of boron-doped (113) oriented homoepitaxial diamond layers. Diamond and Related Materials. 2021, vol. 111, p. 108223.

[2] PINAULT-THAURY, M.-A., TEMGOUA, S., GILLET, R., BENSALAH, H., STENGER, I., JOMARD, F., ISSAOUI, R., BARJON, J. Phosphorus-doped (113) CVD diamond: A breakthrough towards bipolar diamond devices. Applied Physics Letters. 2019, vol. 114, p.112106.

[3] TALLAIRE, A., VALENTIN, A., MILLE, V., WILLIAM, L., PINAULT-THAURY, MA, JOMARD, F., BARJON, J., ACHARD, J. Growth of thick and heavily boron-doped (113)-oriented CVD diamond films. Diamond and Related Materials. 2016, vol. 66, pp. 61-66.

[4] MORTET, V., ŽIVCOVÁ, ZV, TAYLOR, A., DAVYDOVÁ, M., FRANK, O., HUBÍK, P., LORINCIK, J., ALESHIN, M. Determination of atomic boron concentration in heavily boron-doped diamond by Raman spectroscopy. Diamond and Related Materials. 2019, vol. 93, pp. 54-58.

[5] TALLAIRE, A., KASU, M., UEDA, K., MAKIMOTO, T. Origin of growth defects in CVD diamond epitaxial films, Diamond and Related Materials. 2008, vol. 17, pp. 60-65. 